\title{
Human pathogens and vaccine development: New perspective
}

\author{
Pooja Sanduja $^{1}$, Abhinay Sharma ${ }^{1}$, Meenakshi Dua ${ }^{2}$ and Atul KJohri ${ }^{1 *}$ \\ ${ }^{1}$ School of Life Sciences, Jawaharlal Nehru University, India \\ ${ }^{2}$ School of Environmental Sciences, Jawaharlal Nehru University, India
}

\section{Introduction}

Infectious diseases remain one of the most important causes of death and disabilities in the world. Lack of effective treatment against infectious diseases and development of the resistance in pathogens forced the researchers to develop new vaccines or to significantly improve the effectiveness of currently available vaccines. In the past, conventional approaches have been followed for vaccine development. For example, the "first generation" vaccines were developed based on the use of inactivated or live attenuated pathogens. The "second generation" vaccines are purified microbial cell components and referred to as subunit vaccines. The "third generation" of vaccines is currently under development with the use of bioinformatics, genomics, proteomics and associated techniques. Conventional approaches take 5-15 years in order to develop vaccines [1,2].

With the advent of the genome sequences, a more detailed understanding of microbial infection may be achieved at the molecular level. It is now possible to generate the genome sequence information of a human pathogen in 1-2 years at low cost [2]. The generated genomic information can be used to screen the inclusive set of potential proteins/genes encoded by pathogens in the search of vaccine candidates. Furthermore, available multi-genome sequences of same species can be used to identify a core set of genes as well as a variable set of genes differentially expressed in pathogenic strains in comparison to non-pathogenic strains.

AIDS, malaria, tuberculosis, typhoid, meningitis, dengue, and diseases caused by HIV, Plasmodium, Mycobacterium, Streptococcus, Salmonella, Influenza and other pathogens are the major concerns for vaccine research. The biggest challenge for vaccine development is against highly variable and fastly evolving human pathogen [3]. In order to identify vaccine candidates, 'reverse vaccinology' approach would be of high significance as it is less time consuming, not expensive, and also provide crucial information for many infectious diseases for which conventional approaches are not useful or are failed. The successful use of multigenome analysis, screening, and use of proteomics approach to develop a universal vaccine against highly variable pathogen may open new avenues for the successful development of universal protein-based vaccines for other infectious organisms for which suitable vaccines are either not available or need improvement $[4,5]$.

It is also a known fact that, despite the availability of the genome information for faster target identification, we are still involved with the time-consuming validation steps that are performed using conventional approaches. An additional application of protein microarray and nanoproteomics will revolutionize the vaccine research in which identification of potential vaccine candidates would become faster and more authentic $[2,6]$. Furthermore, it will reduce the antigen validation burden and increase the success rate of vaccine development

by selecting the most relevant vaccine candidates using genome-based technologies. In addition, AFM is a powerful technique which would be very handy to identify proteins of surface origin and to measure their binding capacity and hydrophobic nature. Protein microarray and AFM complement classical proteomic and molecular biology approaches for the functional validation of surface proteins, which may help in the identification of novel antimicrobial drugs and vaccine [6-8]

Serotype diversity of infectious organisms is a global problem; therefore a vaccine developed for the prevalent serotypes of developed countries may or may not work in case of developing countries. Therefore, for an effective vaccine development, we need to have accurate epidemiological data of infectious organisms. However, there is a huge shortage in epidemiological data from Africa, Sub-Saharan Africa, Asia, Pacific countries and South America. As economically low and middle-income countries are adversely affected by serious and deadly diseases because of poor hygiene and lack of awareness. Therefore, there is a need to develop collaboration with highincome countries/technologically advanced countries to develop epidemiological centers to fill the gap $[9,10]$.

WHO reports that developing countries are severely affected by most infectious organisms as compared to developed countries [11] Most of the time, cause of infection remains even unidentified in developing countries due to lack of facilities. Therefore, we also need to develop low-priced and effective diagnostic kit for each of diseases caused by above harmful human pathogens. In order to achieve it, (1) we can have a consortium with pharmaceutical companies and other research groups (2) we need to fill the gap in pathophysiology of each diseases and identify marker corresponding to the disease (3) Markers identified for each disease can be exploited to make a universally applicable diagnostic kit (4) Development of a vaccine preparation which should have coverage all over the world.

\section{References}

1. Rappuoli R (2004) From Pasteur to genomics: progress and challenges in infectious diseases. Nat Med 10: 1177-1185. [Crossref]

2. Bagnoli F1, Baudner B, Mishra RP, Bartolini E, Fiaschi L, et al. (2011) Designing the next generation of vaccines for global public health. OMICS 15: 545-566. [Crossref]

3. Delany I, Rappuoli R, De Gregorio E (2014) Vaccines for the 21st century. EMBO Mol Med 6: 708-720. [Crossref]

${ }^{\star}$ Correspondence to: Atul K Johri School of Life Sciences, Jawaharlal Nehru University, New Delhi, India, E-mail: akjohri14@yahoo.com

Received: June 27, 2018; Accepted: August 10, 2018; Published: August 14, 2018 
4. Maione D, Margarit I, Rinaudo CD, Masignani V, Mora M, et al. (2005) Identification of a universal Group B streptococcus vaccine by multiple genome screen. Science 309: 148-150. [Crossref]

5. Bensi G, Mora M, Tuscano G, Biagini M, Chiarot E, et al. (2012) Multi highthroughput approach for highly selective identification of vaccine candidates: the group a streptococcus case. Mol Cell Proteom 11: M111.015693. [Crossref]

6. Jia L, Lu Y, Shao J, Liang XJ, Xu Y (2013) Nanoproteomics: a new sprout from emerging links between nanotechnology and proteomics. Trends Biotechnol 31: 99107. [Crossref]

7. Yi L, Piehowski PD, Shi T, Smith RD, Qian WJ (2017) Advances in microscale separations towards nanoproteomics applications. J Chromatogr A 1523: 40-48. [Crossref]
8. Kobeissy FH, Gulbakan B, Alawieh A, Karam P, Zhang Z, et al. (2014) Post-genomics nanotechnology is gaining momentum: nanoproteomics and applications in life sciences. Omics 18: 111-131. [Crossref]

9. Ameh S, Klipstein-Grobusch K, D'ambruoso L, Kahn K, Tollman SM, et al. (2017) Quality of integrated chronic disease care in rural South Africa: user and provider perspectives. Health Policy Plan. 32: 257-266. [Crossref]

10. Steer AC, Carapetis JR, Dale JB, Fraser JD, Good MF, et al. (2016) Status of research and development of vaccines for Streptococcus pyogenes. Vaccine 34: 2953-2958. [Crossref]

11. Carapetis JR, Steer AC, Mulholland EK, Weber M (2005) The global burden of group A streptococcal diseases. Lancet Infect Dis 5: 685-694. [Crossref]

Copyright: $\odot 2018$ Sanduja P. This is an open-access article distributed under the terms of the Creative Commons Attribution License, which permits unrestricted use, distribution, and reproduction in any medium, provided the original author and source are credited. 